\title{
Solvent Effects on the UV Absorption Spectrum of Carmofur
}

\author{
Peipei Zhang, Shuyu Liu* \\ College of Chemistry and Chemical Engineering, Shanghai University of Engineering Science, Shanghai, China \\ Email: "liushuyu1219@163.com
}

Received 24 December 2015; accepted 19 January 2016; published 22 January 2016

Copyright (C) 2016 by authors and Scientific Research Publishing Inc.

This work is licensed under the Creative Commons Attribution International License (CC BY).

http://creativecommons.org/licenses/by/4.0/

(c) (i) Open Access

\begin{abstract}
In this article, we reported that carmofur could be induced by some solvent to produce conformational alteration. Ultraviolet (UV) spectra were used to study the conformation alteration of carmofur. Upon the addition of acid in the some solvent, UV spectroscopy of carmofur could change gradually. When base was added to this system, UV spectroscopy of carmofur could return to the original state, and the change process was reversible. The variable temperature ${ }^{1} \mathrm{H}$ and ${ }^{13} \mathrm{C}$-NMR spectrum were used to testify that temperature did not have any effect on the conformation alteration of carmofur in Acetonitrile: Trifluoroacetic-acid (9:1). These two conformers of carmofur were structurally stable in Acetonitrile: Trifluoroacetic-acid (9:1).
\end{abstract}

\section{Keywords}

Solvent-Induced, Carmofur, Conformation, UV Spectra

\section{Introduction}

1-Hexylcarbamoyl-5-fluorouracil or carmofur (HCFU) (Figure 1) has an antineoplastic effect and is used to treat patients with solid tumors, such as breast and gastrointestinal carcinomas [1]. Carmofur appeared to be the most promising antitumor agent when administered orally in that carmofur retains well balanced lipo- and hydro-philicity, and decomposed moderately in a tumor [2]. Nevertheless, carmofur still has toxicity and limited antitumor activity in clinically. It is considered that the chemical structure of carmofur relates to the rapid uptake of carmofur, because the hexylcarbamoyl structure (C-N bond) facilitates rapid absorption through the gastrointestinal tract and blood-ascities barrier [2].

At present, the catalysis of carmofur's conformational alteration in organic solvent by chemical equivalent

*Corresponding author. 


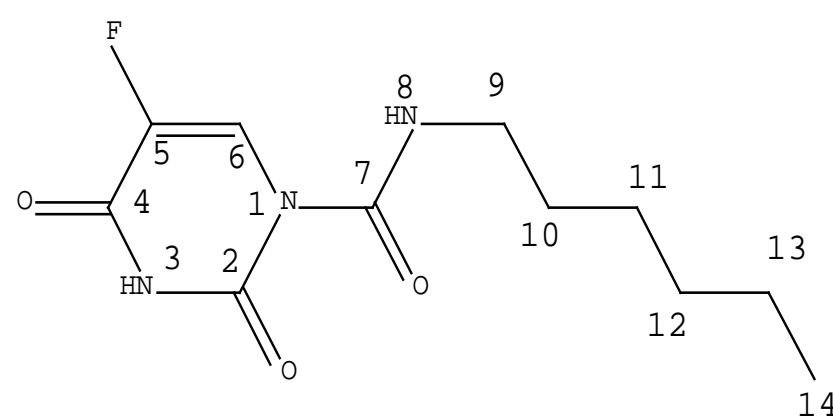

Figure 1. Chemical structure of carmofur.

amounts of acid has not been demonstrated. Here, we studied acid/base induced conformational alteration of carmofur in solvent via using UV-Vis spectroscopy [3]-[9]. We reported that UV spectroscopy of carmofur in the some solvent changed gradually with the addition of acid. The above experimental result revealed that carmofur could be induced to produce chemical conformational alteration phenomena under the condition of acid solution.

\section{Materials and Methods}

\subsection{Materials}

Carmofur was obtained from Shanghai Oriental Pharmaceutical Science and Technology Co. Ltd. Acetonitrile $\left(\mathrm{CH}_{3} \mathrm{CN}\right)$, Methanol $\left(\mathrm{CH}_{3} \mathrm{OH}\right)$, Ethanol $\left(\mathrm{CH}_{3} \mathrm{CH}_{2} \mathrm{OH}\right)$ and Acetic acid $\left(\mathrm{CH}_{3} \mathrm{COOH}\right)$ were purchased from Shanghai crystal pure biological technology co., Ltd. Trifluoroacetic-acid (TFA), Formic acid (HCOOH), Triethylamine $\left(\mathrm{Et}_{3} \mathrm{~N}\right)$ and ammonium solution $\left(\mathrm{NH}_{3}, 25 \%\right)$ were purchased from Shanghai Ling Feng Chemical Reagent Co., Ltd. Sodium hydroxide ( $\mathrm{NaOH})$ is purchased from Sinopharm Chemical Reagent Co., Ltd.

\subsection{Experimental Instrument}

In our study, some instruments were used as follows DMX 500 Nuclear Magnetic Resonance Spectrometer (Brucker Germany), Shimadzu UV-1601PC instrument (Japan Shimadzu), AB135-s electronic balance (Switzerland METTLER TOLEDO), Color plate (Yixing crystal optical instrument co., LTD.) and pipetting gun (Shanghai Hanlin Experimental Instrument Co., Ltd.).

\subsection{UV Spectroscopy Condition}

Scanning wavelength: $200 \mathrm{~nm}$ - $400 \mathrm{~nm}$; Absorbance range: 0.0 - 2.0.

All the Experimental data were recorded at $298 \mathrm{~K}$.

\subsection{Experiment Method}

Solvent: Acetonitrile $\left(\mathrm{CH}_{3} \mathrm{CN}\right)$, Methanol $\left(\mathrm{CH}_{3} \mathrm{OH}\right)$, Ethanol $\left(\mathrm{CH}_{3} \mathrm{CH}_{2} \mathrm{OH}\right)$.

Acid: Trifluoroacetic-acid (TFA), Acetic acid $\left(\mathrm{CH}_{3} \mathrm{COOH}\right)$, Formic acid (HCOOH), Base: Triethylamine $\left(\mathrm{Et}_{3} \mathrm{~N}\right)$, Sodium hydroxid solution $(0.2 \mathrm{~g} / \mathrm{ml})$, Ammonium solution $\left(\mathrm{NH}_{3}, 25 \%\right)$.

UV measurements were made on a spectrometer. Firstly, we measured precisely1ml carmofur solution (1 mg carmofur dissolved in $10 \mathrm{ml}$ acetonitrile) by the pipetting gun, addition to $2 \mathrm{ml}$ solvent. Then, a certain amount of acid was added to the above acetonitrile solution of carmofur respectively. The base was added to carmofur dissolved in acetonitrile containing a certain equivalent of acid.

The variable-temperature ${ }^{1} \mathrm{H}$ and ${ }^{13} \mathrm{C}$ NMR of carmofur were recorded on the same equipment in Acetonitrile: Trifluoroacetic-acid $(9: 1)$ at $-10^{\circ} \mathrm{C}, 10^{\circ} \mathrm{C}, 20^{\circ} \mathrm{C}, 40^{\circ} \mathrm{C}, 60^{\circ} \mathrm{C}, 70^{\circ} \mathrm{C}$.

\section{Results and Discussions}

\subsection{UV Spectroscopy Analysis}

In the process of UV absorption spectra test, we found that UV spectroscopy of carmofur could change clearly 
in $\mathrm{CH}_{3} \mathrm{CN}$. Upon titration of the carmofur solution with TFA, the absorption band centered at $\lambda_{\max }=213 \mathrm{~nm}$ gradually disappears (Figure 2). Because of the addition of trifluoroacetic acid, the solvent polarity and dipole increased, resulting in the polarity of the solute increased. It also caused the maximum wavelength red shift and decreased the absorbance. The result showed that $\pi$ bonding orbital of carmofur structure jumped into antibonding orbital. When $\mathrm{Et}_{3} \mathrm{~N}$ was added to the protonated solution, the original spectrum centered at $\lambda_{\max }=213$ $\mathrm{nm}$ is steadily regained. This is because anti-bonding orbital of carmofur structure jumped back into $\pi$ bonding orbital. From this change phenomenon, it is apparent to show that the acid/base switching process in $\mathrm{CH}_{3} \mathrm{CN}$ is fully reversible.

The result indicated the addition of TFA in $\mathrm{CH}_{3} \mathrm{CN}$ could induce conformational alteration of carmofur and $\mathrm{Et}_{3} \mathrm{~N}$ could make the altered conformation of carmofur back to the original conformation. The acid/base induced amide conformational alteration process was reversible. We found that $\mathrm{NaOH}\left(0.2 \mathrm{mg} / \mathrm{cm}^{3}\right)$ and $\mathrm{NH}_{3}$ also could make the altered conformation of carmofur back to the original conformation. (Figure 2)

In Figure 3, the UV spectra indicated the addition of $\mathrm{CH}_{3} \mathrm{COOH}$ in $\mathrm{CH}_{3} \mathrm{CN}$ could induce conformational alteration of carmofur. In the protonated solution by $\mathrm{CH}_{3} \mathrm{COOH}, \mathrm{Et} 3 \mathrm{~N} / \mathrm{NaOH}\left(0.2 \mathrm{mg} / \mathrm{cm}^{3}\right) / \mathrm{NH}_{3}$ could make the altered conformation of carmofur back to the original conformation.

In Figure 4, the UV spectra indicated the addition of $\mathrm{HCOOH}$ in $\mathrm{CH}_{3} \mathrm{CN}$ could induce amide conformational alteration of carmofur. In the protonated solution by $\mathrm{HCOOH}, \mathrm{Et}_{3} \mathrm{~N} / \mathrm{NaOH}\left(0.2 \mathrm{mg} / \mathrm{cm}^{3}\right) / \mathrm{NH}_{3}$ could make the altered conformation of carmofur back to the original conformation.

There are the same phenomenon of carmofur in solvents such as $\mathrm{CH}_{3} \mathrm{CH}_{2} \mathrm{OH}$ and $\mathrm{CH}_{3} \mathrm{OH}$. The addition of $\mathrm{HCOOH} / \mathrm{TFA} / \mathrm{CH}_{3} \mathrm{COOHin} \mathrm{CH}_{3} \mathrm{CH}_{2} \mathrm{OH} / \mathrm{CH}_{3} \mathrm{OH}$ could induce conformational alteration of carmofur. In the
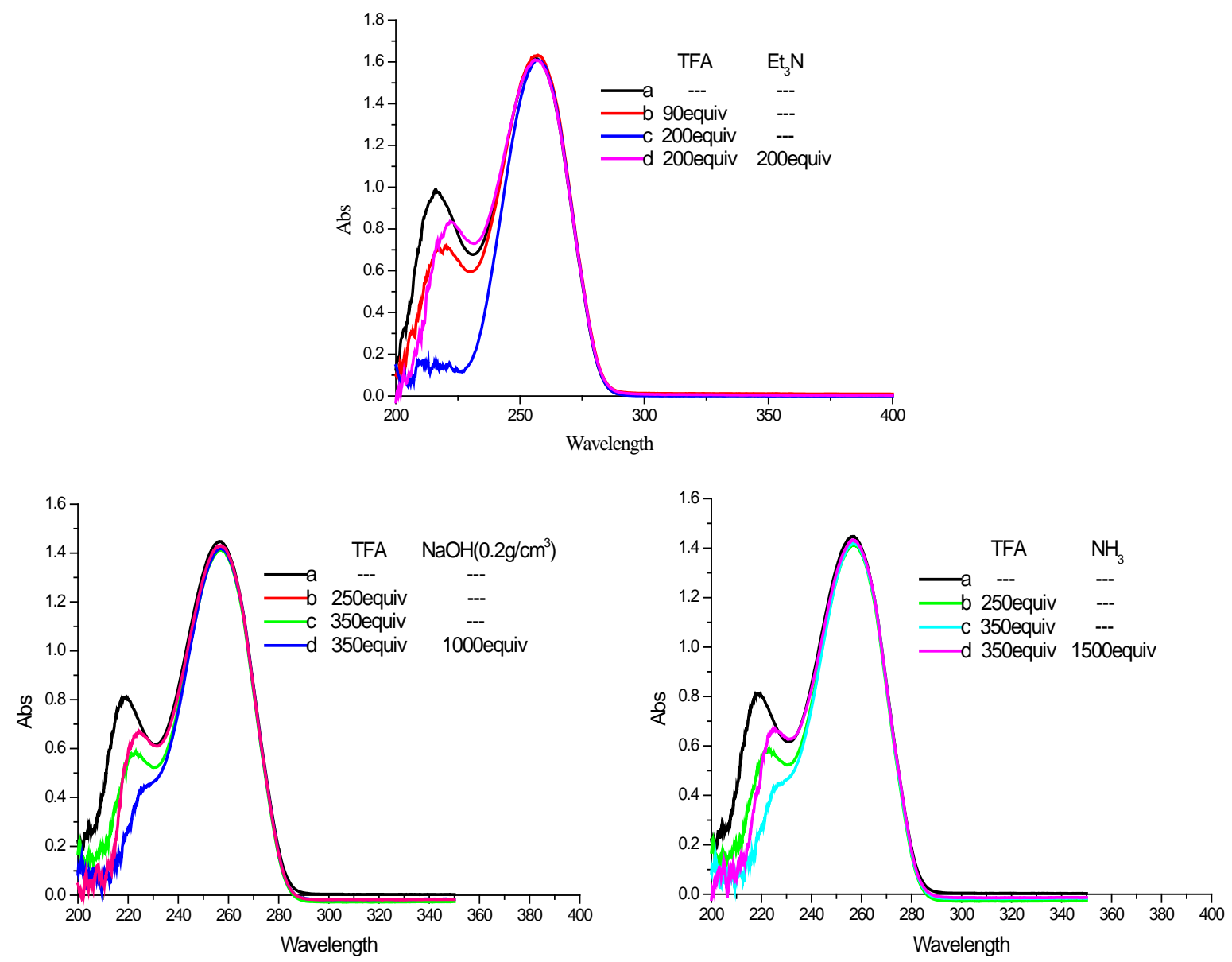

Figure 2. Change in the UV spectra in the solvent of $\mathrm{CH}_{3} \mathrm{CN}$. The equivalents of TFA was added to a, then the equivalents of TFA was added to b, until there was no observable change c. $\mathrm{Et}_{3} \mathrm{~N}, \mathrm{NaOH}\left(0.2 \mathrm{mg} / \mathrm{cm}^{3}\right)$ or $\mathrm{NH}_{3}$ was added c to switch the system back d, respectively. 

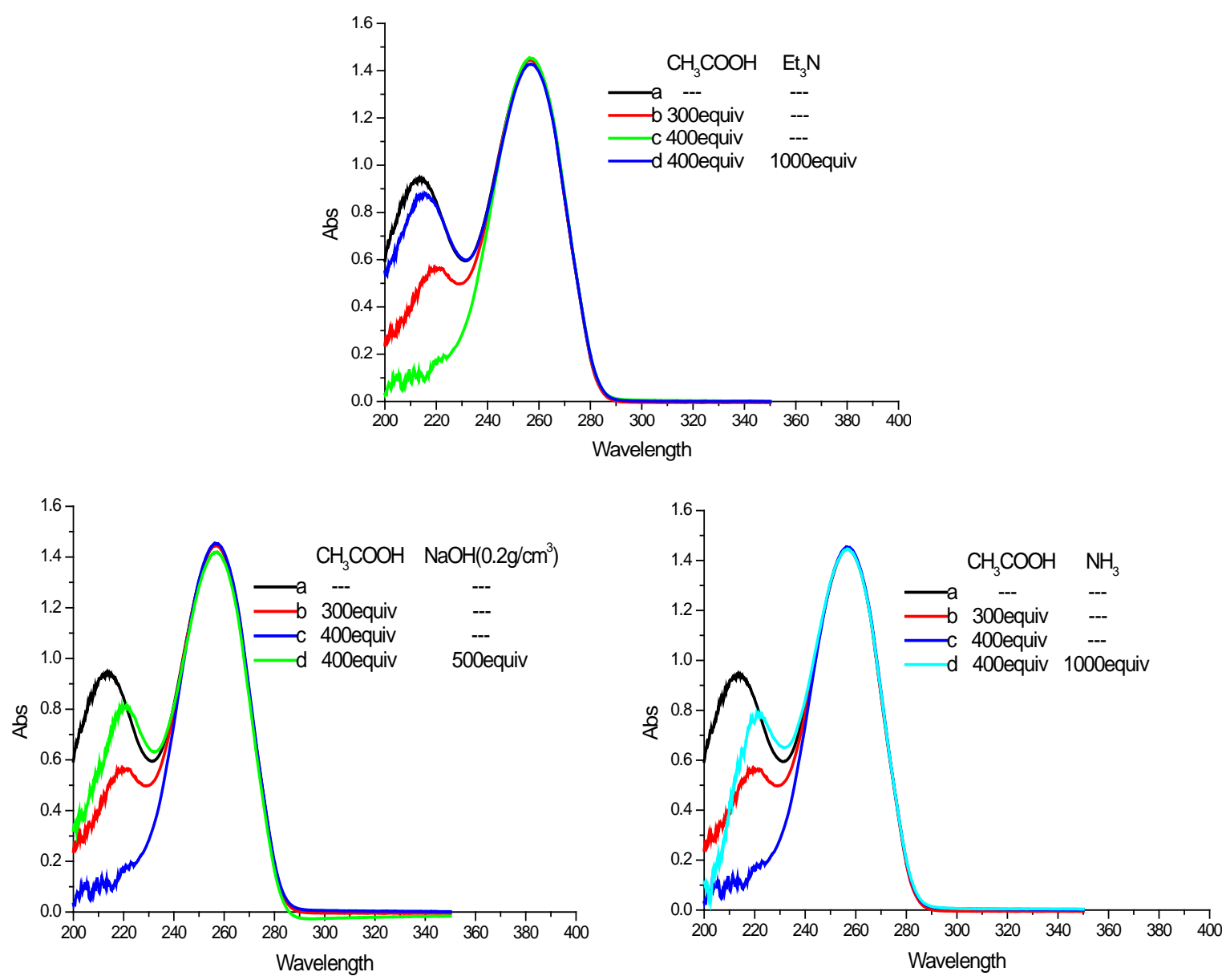

Figure 3. Change in the UV spectra in the solvent of $\mathrm{CH}_{3} \mathrm{CN} .300$ equivalents of $\mathrm{CH}_{3} \mathrm{COOH}$ was added to a, then 400 equivalents of $\mathrm{CH}_{3} \mathrm{COOH}$ was added to b, until there was no observable change $\mathrm{c}$. $\mathrm{Et}_{3} \mathrm{~N}, \mathrm{NaOH}\left(0.2 \mathrm{mg} / \mathrm{cm}^{3}\right)$ or $\mathrm{NH}_{3}$ was added c to switch the system back d, respectively.

protonated solution, $\mathrm{Et}_{3} \mathrm{~N} / \mathrm{NaOH} / \mathrm{NH}_{3}$ Could make the altered conformation of carmofur back to the original conformation.

In addition, we also did likewise experiment with inorganic acid, such as sulfuric acid, hydrochloric acid and phosphoric acid. When sulfuric acid, hydrochloric acidor phosphoric acid was added to the carmofur solution respectively, UV spectroscopy of carmofur had no obvious change. Inorganic acid (sulfuric acid, hydrochloric acid and phosphoric acid) could not induce conformational alteration of carmofur.

\subsection{Variable-Temperature ${ }^{1} \mathrm{H}$ and ${ }^{13} \mathrm{C}$ NMR Analysis}

In the variable temperature ${ }^{13} \mathrm{C}$-NMR spectrum of carmofur in Acetonitrile: Trifluoroacetic-acid (9:1), we found that ${ }^{13} \mathrm{C}-\mathrm{NMR}$ spectrum of carmofur contains two kinds of data at room temperature (Figure 5). The result showed that there were two conformers of carmofur in Acetonitrile: Trifluoroacetic-acid (9:1) at room temperature, which is due to the partially double-bond character of carmofur's amide bond at $20^{\circ} \mathrm{C}$. Meawhile, in the variable temperature ${ }^{1} \mathrm{H}-\mathrm{NMR}$ spectrum of carmofur in Acetonitrile: Trifluoroacetic-acid (9:1), ${ }^{1} \mathrm{H}-\mathrm{NMR}$ spectrum of carmofur appeared only a set of data at room temperature (Figure 6). The phenomena showed ${ }^{1} \mathrm{H}-\mathrm{NMR}$ spectrum of two conformers of carmofur were the same.

Along with the gradual increase in temperature to $70{ }^{\circ} \mathrm{C},{ }^{13} \mathrm{C}-\mathrm{NMR}$ spectrum of carmofur revealed that these two kinds of data remain the same proportion and have no any other changes (Figure 7). When discreasing temperature to $-10^{\circ} \mathrm{C}$, these two kinds of data still had no any changes (Figure 7). As we can see from Figure 6, ${ }^{1} \mathrm{H}$-NMR spectrum of carmofur appeared no any changes at the different temperature. The above experimental 

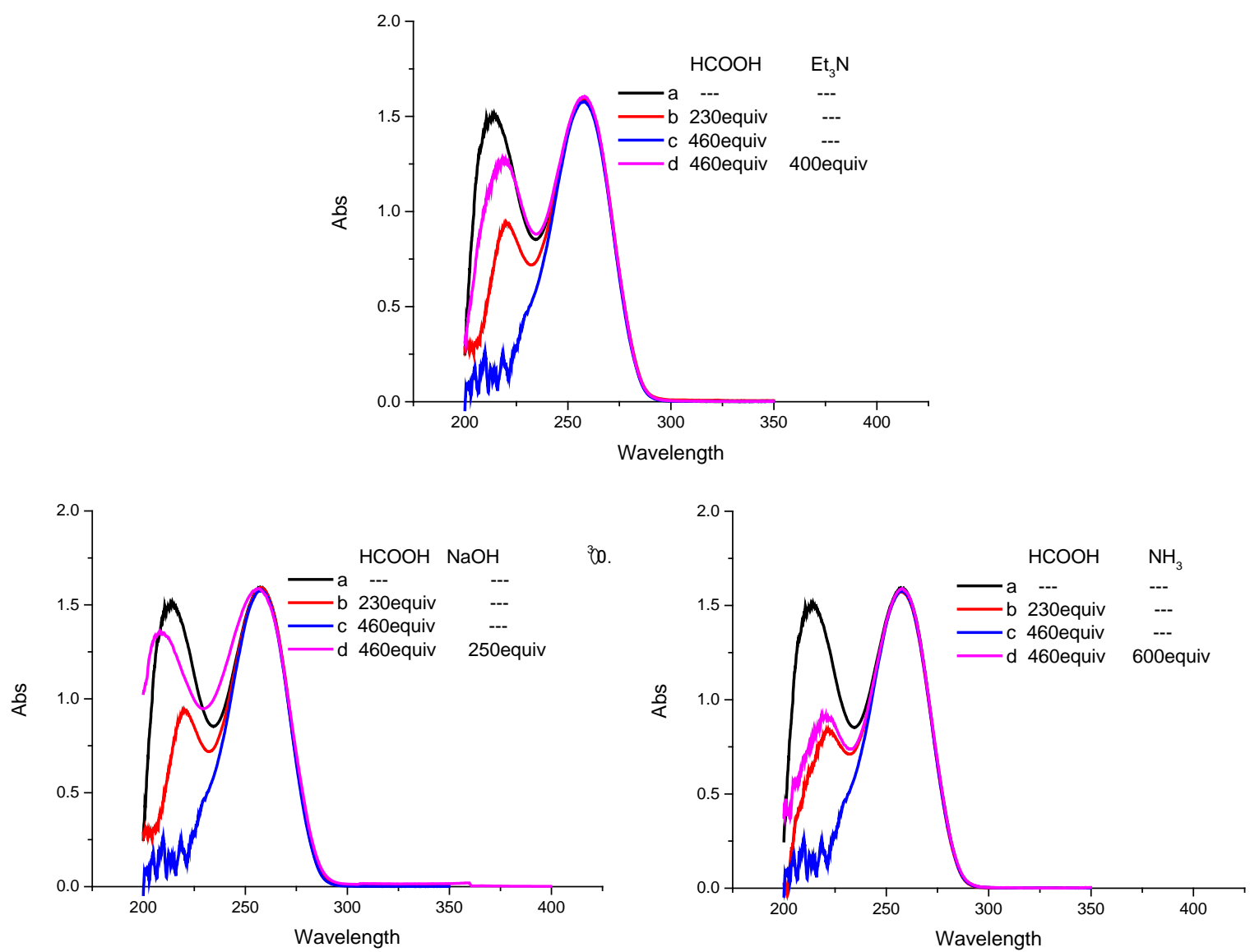

Figure 4. Change in the UV spectra in the solvent of $\mathrm{CH}_{3} \mathrm{CN}$. 230 equivalents of $\mathrm{HCOOH}$ was added to a, then 460 equivalents of $\mathrm{HCOOH}$ was added to b, Until there was no observable change c. $\mathrm{Et}_{3} \mathrm{~N}, \mathrm{NaOH}\left(0.2 \mathrm{mg} / \mathrm{cm}^{3}\right)$, $\mathrm{NH}_{3}$ were added c to switch the system back d, respectively.

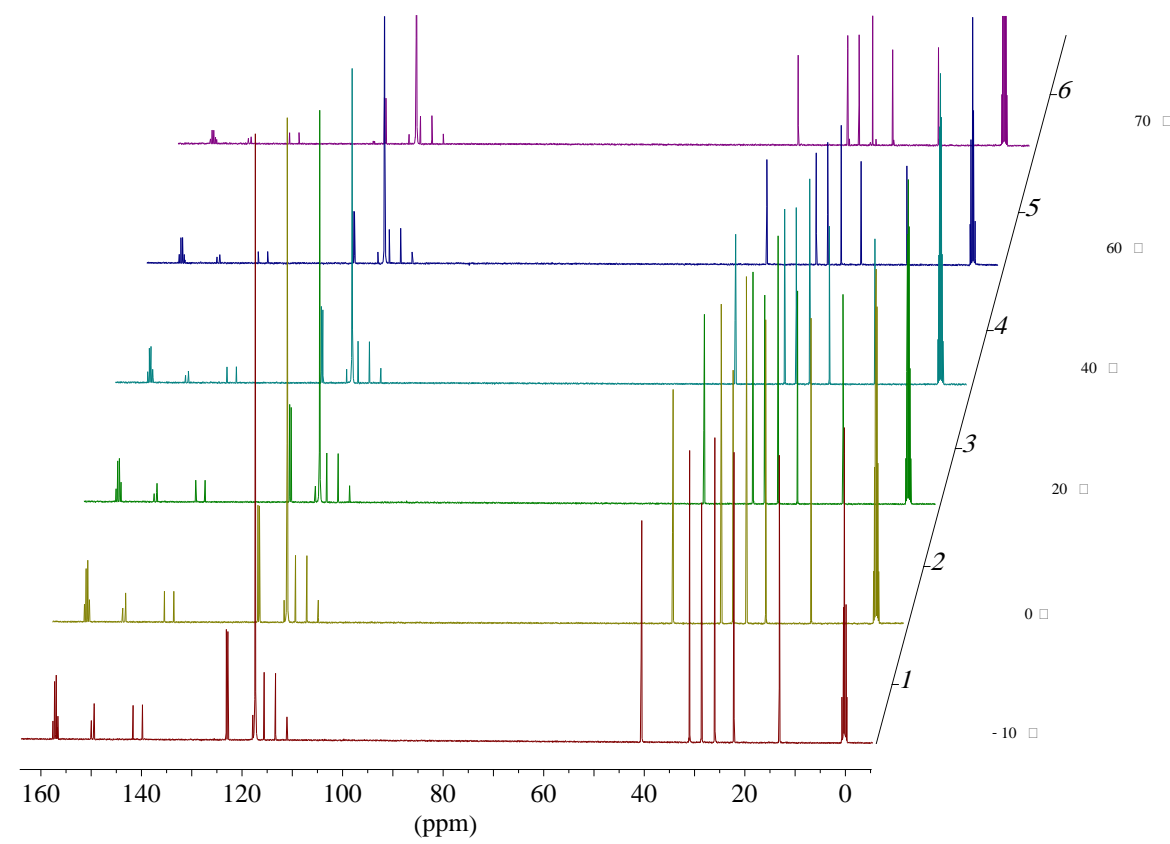

Figure 5. Variable temperature ${ }^{13} \mathrm{C}-\mathrm{NMR}$ spectrum of carmofur. 


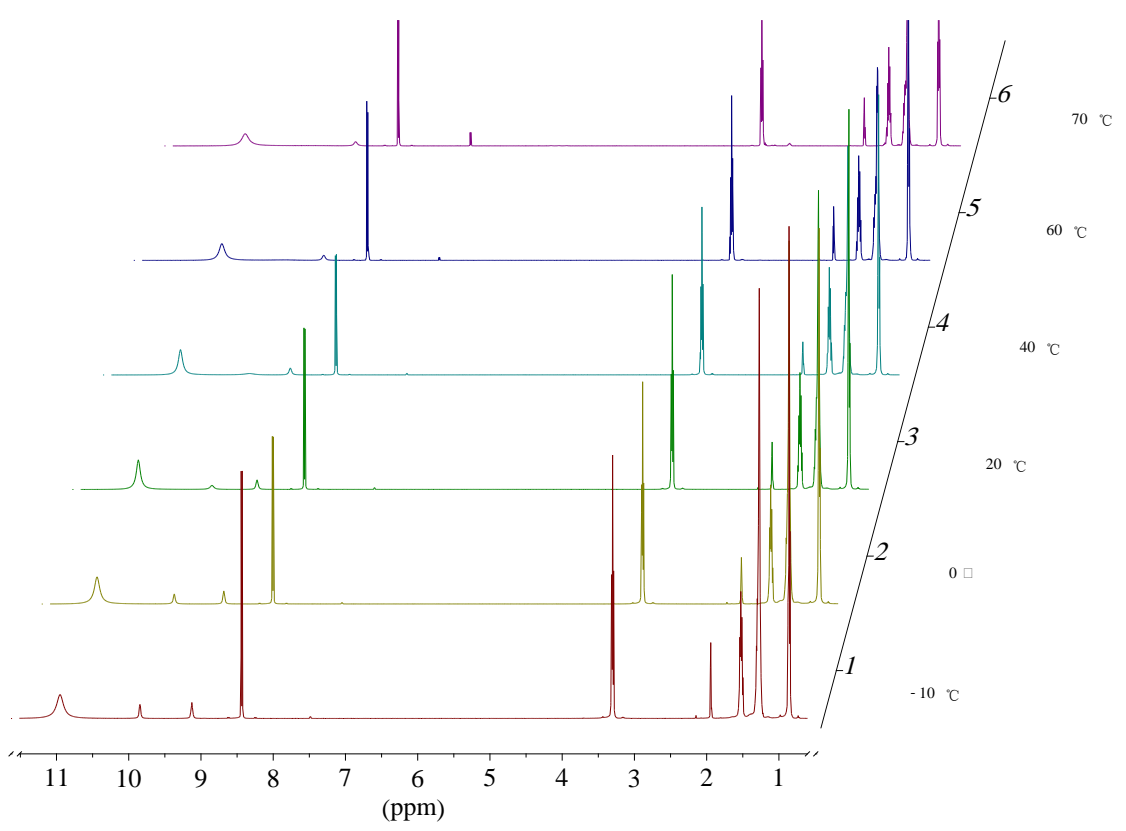

Figure 6. Variabletemperature ${ }^{1} \mathrm{H}-\mathrm{NMR}$ spectrum of carmofur.

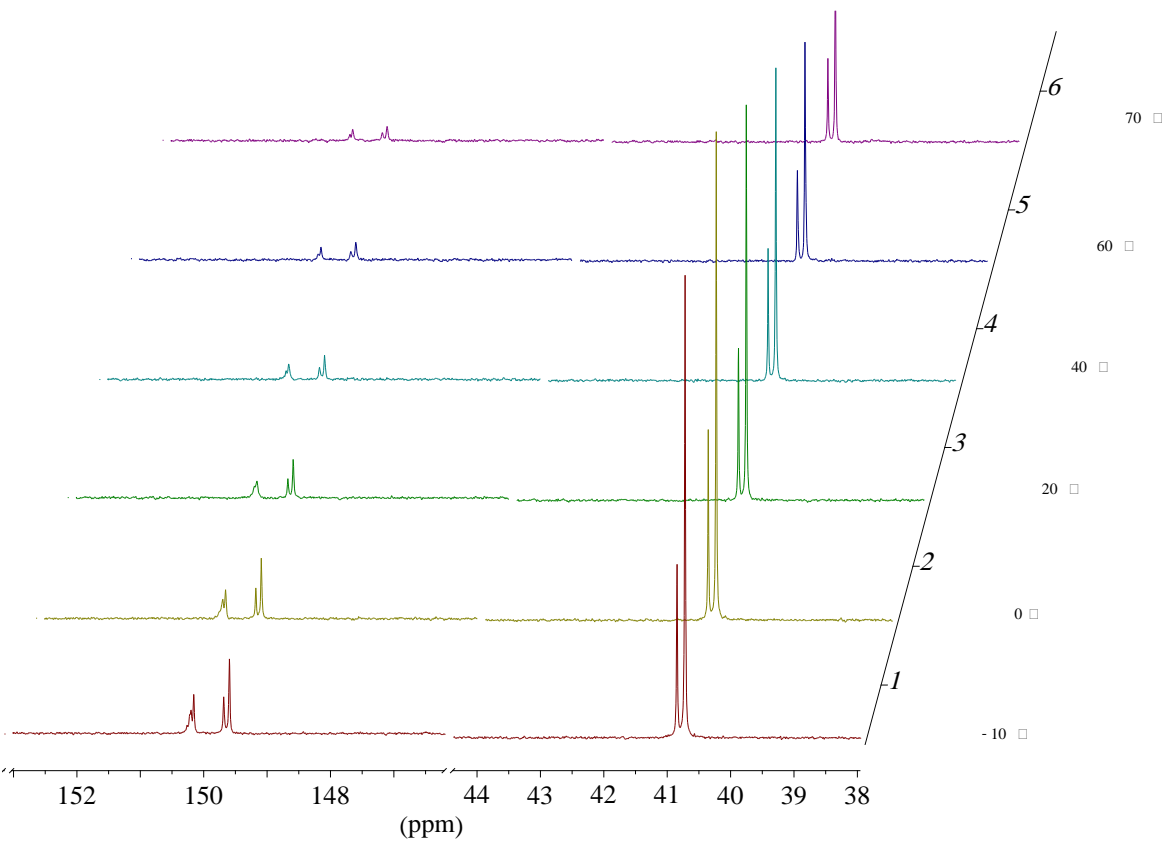

Figure 7. Variable temperature ${ }^{13} \mathrm{C}-\mathrm{NMR}$ partial enlargedspectrum of carmofur.

phenomena testified that temperature did not have any effect on these two conformers of carmofur in Acetonitrile: Trifluoroacetic-acid (9:1). These two conformers of carmofur were structurally stable in Acetonitrile: Trifluoroacetic-acid (9:1).

\section{Conclusions}

The result indicated that the addition of acid (Trifluoroacetic-acid, Acetic acid, Formic acid) in the some solvent (Acetonitrile, Methanol, Ethanol) could induce conformational alteration of carmofur and the base (Triethylamine, Sodium hydroxidesolution $\left(0.2 \mathrm{~g} / \mathrm{cm}^{3}\right)$, Ammonium solution (25\%)) could make the altered conformation 
of carmofur back to the original conformation. The conformational alteration process was reversible. Moreover, inorganic acid (Trifluoroacetic-acid, Acetic acid, Formic acid) could induce the conformation alteration of carmofur, but inorganic acid (sulfuric acid, hydrochloric acid, phosphoric acid) could not.

The variable temperature ${ }^{13} \mathrm{C}$-NMR spectrum also testified that there were two conformers of carmofur in Acetonitrile: Trifluoroacetic-acid (9:1) at room temperature. And the variable temperature ${ }^{1} \mathrm{H}$ and ${ }^{13} \mathrm{C}-\mathrm{NMR}$ spectrum indicated that temperature did not have any effect on these two conformers of carmofur in Acetonitrile: Trifluoroacetic-acid (9:1). These two conformers of carmofur were structurally stable in Acetonitrile: Trifluoroacetic-acid (9:1).

\section{Acknowledgements}

The study was financed by the graduate research and innovation funding (14KY0412). We would like to thank Shanghai University of Engineering Science for financial support.

\section{References}

[1] Liu, Y.W., Wang, C.X., Zheng, C.Y., Wang, Z.Y., Wu, H.X. and Qu, S.S. (2001) Microcalorimetric Study on the Enhanced Antitumor Effects of 1-Hexylcarbamoyl-5-fluorouracil by Combination with Hyperthermia on K-562 Cell Line. Thermochimica Acta, 369, 51-57. http://dx.doi.org/10.1016/S0040-6031(00)00754-1

[2] Maehara, Y., Kusumoto, H., Anai, H., Kusumoto, T., Hiramoto, Y. and Sugimachi, K. (1987) 1-Hexylcarbamoyl-5fluorouracil Is More Cytostatic than 5-Fluorouracil against Human Tumors in Vitro. European Journal of Cancer and Clinical Oncology, 23, 1511-1515. http://dx.doi.org/10.1016/0277-5379(87)90094-0

[3] Landge, S.M. and Aprahamian, I. (2009) apH Activated Conformational Rotary Switch: Controlling the E/Z Isomerization in Hydrazones. Journal of the American Chemical Society, 131, 18269-18271. http://dx.doi.org/10.1021/ja909149z

[4] Okamoto, I., Terashima, M., Masu, H., Nabeta, M., Ono, K., Morita, N., Katagiri, K., Azumaya, I. and Tamura, O. (2011) Acid-Induced Conformational Alteration of Cis-Preferential Aromatic Amides Bearing N-Methyl-N-(2-pyridyl) Moiety. Tetrahedron, 67, 8536-8543. http://dx.doi.org/10.1016/j.tet.2011.08.085

[5] Gardner, R.R., Mckay, S.L. and Gellman, S.H. (2000) Solvent-Dependent Stabilization of the E Conformation of Propargylic Secondary Amides. Organic Letters, 2, 2335-2338. http://dx.doi.org/10.1021/ol006096j

[6] Liao, C.Y., Chan, K.T., Chang, Y.C., Chen, C.Y., Tu, C.Y., Hu, C.H. and Lee, H.M. (2007) Unexpected Solvent Induced Z/E Isomerization and Catalytic Application of a Bis-Bidentate Nickel(II) Complex with N-Heterocyclic Carbene and Amido Functionalities. Organometallics, 26, 5826-5833. http://dx.doi.org/10.1021/om700607m

[7] Koshevoy, I.O., Chang, Y.C., Karttunen, A.J., Haukka, M., Pakkanen, T. and Chou, P.T. (2012) Modulation of Metallophilic Bonds: Solvent-Induced Isomerization and Lumine-Scence Vapochromism of a Polymorphic Au-Cu Cluster. Journal of the American Chemical Society, 134, 6564-6567. http://dx.doi.org/10.1021/ja3018994

[8] Li, P., Alduhaish, O., Arman, H.D., Wang, H.L., Alfooty, K. and Chen, B. (2014) Solvent Dependent Structures of Hydrogen-Bonded Organic Frameworks of 2,6-Diaminopurine. American Chemical Society, 14, 3634-3638. http://dx.doi.org/10.1021/cg500602x

[9] Mijin, D.Ž., Ušćumlića, G.S., Perišić-Janjićb, N.U. and Valentić, N.V. (2006) Substituent and Solvent Effects on the UV/Vis Absorption Spectra of 5-(3- and 4-Substituted arylazo)-4,6-dimethyl-3-cyano-2-pyridones.Chemical Physics Letters, 418, 223-229. http://dx.doi.org/10.1016/j.cplett.2005.10.130 